\title{
The Empirical Application of Task-based Language Teaching to English Speaking Classroom
}

\author{
Xin Cui \\ School of Humanities and Social Sciences \\ Xi'an Polytechnic University \\ Xi'an, China
}

\begin{abstract}
This paper would provide a general overview of TBLT approach based on evaluating the actual 40 minutes TBL speaking class that draw on my individual teaching experiences. It attempts to illustrate that TBLT approach can be feasible and effective for the EFL speaking teaching classroom.
\end{abstract}

Keywords—task-based language teaching (TBLT); EFL; speaking class

\section{INTRODUCTION}

Over the past several decades, task-based language teaching (TBLT) has been increasingly advocated and promoted by a number of SLA (second language acquisition) researchers, curriculum designers, and educational innovators (Long 1985, Prabhu 1987, Nunan 1989, Willis 1996, Skehan 1998, Bygate \&Ellis 2001). Despite some differences these scholars may hold, a broad consensus on the norm of TBLT has been gradually achieved. Generally speaking, TBLT approach takes much emphasis on studentcentered learning, requiring their language proficiency should be acquired naturally by doing meaningful tasks (Nunan, 1989). This norm of TBLT approach indicates that in a TBL class, the language teacher promotes the target language learning through engaging student in meaningful communication when they carry out functional tasks that based on a genuine context (Willis, 1996). In the light of this fundamental concept, TBLT, as the type of teaching methodology implicating the nexus of theories and principles has been practiced in the EFL (English as foreign language) teaching class.

This paper would provide a general overview of TBLT approach based on evaluating the actual 40 minutes TBL speaking class that draw on my individual teaching experiences. It attempts to illustrate that TBLT approach can be feasible and effective for the EFL speaking teaching classroom. The article will begins by consideration of student's context in this TBL speaking class, followed by the theoretical and empirical illustration of its task and the implement of framework, and finally the article will mainly give great concern on the process of task assessment.

\section{RELEVANCE TO THE TBL SPEAKING LESSON DESIGN}

\section{A. Students' Profile}

Any TBL class designed should take a primary consideration on the students' profile. Based on the concept of TBLT approach, one of the most important characteristic of TBL lessons is student-centered learning paradigm, which means students play a domain role in the whole process of lesson. It demands that a TBL class would draw knowledge from students, working through their needs and interests and selecting materials, activities and tasks accordingly (Branden, K., 2006). Therefore, it is important for a TBL class to identify the target students' general profile.

In the current empirical class, there are four Chinese students are involve in and they have nearly the same academic background. All of them are up-intermediate English speakers and their first language is mandarin. They come to UK to pursue their advanced studies and have resided within UK for periods of six to nine months, and also four of them will graduate in couple of months.

\section{B. The Definition of Task}

Regarding the target students' profile, this TBL speaking class will be comprehensive further promoted. At the first priority, the TBL class need to seek what tasks should be involved in the lesson syllabus. In TBL classroom, the task is the central foundation for TBLT approach. The concept of "task" is interpreted by numerous linguists in various ways. Normally, the term of 'task' is defined in two categories. In a broad understanding, the task is meant "the hundred and one things people do in everyday life, at work, at play and in between" (Long, 1985, p.89). This definition is a nonpedagogical interpretation in that it mentioned the sorts of things that outside the classroom and some of these tasks do not necessarily refer to the use of language. However, in order to integrate 'task' into the language teaching classroom, Richards, Platt, \&Weber (1986, p.289) offered a more pedagogically oriented definition, that is "an activity or action which is carried out as the result of processing or understanding language". This definition implies that tasks involving in the target communicative language will attract the L2 user's focus on meaning instead of linguistics form. 
Blending these two types of definition, Skehan (1998) further summarizes some principles of tasks in a TBL classroom. The first one is class tasks should have practical meanings, that is to say, the target language students use in class can be applied to their real-life communications. Secondly, class tasks should have moderate difficulty. Students will easily lose interest in activities if the tasks are too simple or too difficult. Thirdly, class tasks need to be coherence and integrity. It is inappropriate that a TBL class has several scattered tasks without any relationship with each other. On the contrary, specific tasks for each task process should be clearly known by teachers and students.

On account of the above definition and principles, this empirical TBL speaking class formulates its own tasks. Considering the target students possess relative high level of English proficiency and also they will soon graduate, the ensemble task is how to prepare good answers for an English job interview. Such general task can be identified as both the target task and pedagogical task. Students engage in a job interview that actually happen in a real daily life. Meanwhile, response questions in a job interview will possibly create the communicative opportunity of target language among students. Such interaction naturally conveys certain meaning and information. Therefore the whole TBL class caters to meaning-focus TBLT principle. Also, students are required to using the target language in the job interview, which increase certain complexity and diversity. It is not easy for students to use the target language to promote the process of communication and also the content of job interview need them motivate their own different personal experience and knowledge to construct.

\section{THE FRAMEWORK AND IMPLEMENTATION OF THE TBL SPEAKING CLASS}

Concerning intrinsic quality of meaning-focus on the TBL class, the whole speaking class has been associated with an emphasis on fluency rather than accuracy. Based on this view, this empirical class decide to cope with Willis' $s$ (1996) framework of the TBL class that utilized the format of pre-task, task cycle and language focus. This paradigm aim to create the optimum conditions for language acquiring (Willis, 2007).

\section{A. Pre-task Phrase}

This stage serves as an introduction to the topic and task (Willis, 1996). The teacher as a facilitator identifies and introduces the topic and students feel motivated to perform the task (ibid). At the outset, students need to know what task they will be required to do and the nature of the outcome they will arrive at (Lee, 2000). Then, the teacher needs to recall and activate existing schematic knowledge relating the topic and highlight useful information which might be needed during the stage of task cycle.

In this TBL speaking class, since students have clear mind about what is the major task, the teacher will put forward them to share information about job interview that they know or once have similar experience. This is a kind of open task what Willis (1996) called "sharing personal experience". After that, the teacher will introduce a short video that involve in an "ideal" model of job interview demonstrated by native speakers, while students are asked to observe this model of how the task can be performed. Such "observing" others perform can help students reduce the cognitive load and can also be accompanied by activities designed to raise students' consciousness about specific features of the task cycle (Skehan, 1996 and Willis, 1996). In addition, following this video, the teacher will list some key points related with the class task, for example, in that video, the interviewer mentioned their educational background, job experience and personalities to manage their job interview question. These listed points will be used to help students to understand the theme of this class and also provide the background of this class that can pave the way for the next stage. Define abbreviations and acronyms the first time they are used in the text, even after they have been defined in the abstract. Abbreviations such as IEEE, SI, MKS, CGS, sc, dc, and rms do not have to be defined. Do not use abbreviations in the title or heads unless they are unavoidable.

\section{B. Task Cycle Phrase}

The task cycle stage is the core component of the whole process of task implement, which account for 20 minutes in total. It is suggested to divide into the planning phrases and the report phrases that take up 10 minutes respectively. The task cycle purposes on giving learners the opportunity to perform real-world tasks with the teacher's monitoring (Willis, 1996).Specifically, the teacher as a facilitator just provides necessary guideline for students about what they need to undertake in this stage. Then, students control the whole class to plan how to present the outcome of their work. As they took preparation for the play, it will not only increase students' confidence but also helped they more efficiently acquire fluency in the target language. Finally, they report the conclusions they have reached.

At the task-planning phrase of this empirical class, the teacher begins to briefly assign the principal task to students. That is students need to act out a job interview by themselves. After students understand this stage task, the teacher provided some instructions for them to help participants achieve the task smoothly, for example, the teacher recommended students' performance need involve in some useful points that were highlighted in the pre-task phrase, their individual role (the interviewer or interviewee) in this job interview and identify what job they want to apply for. Based on these directions, students engaged in discussion how to perform their job interview. During this process, four students were advisable to work in pairs. Such collaborative learning can greatly lead to more spontaneous, confident and analytical talk (Jaque, 2000). When each pair made full preparation, the teacher further promoted class into the report phrase.

Similarly, in the report phrase still echoes the studentcentered norm of TBLT. The facilitator primly gave student short guideline. That requires each pair of students perform the role-playing job interview in front of the whole class within 4 minute. At the same time, when one group perform, another group need to observe carefully to identify whether 
their job interview integrate with those key points that mentioned in the stage of pre-task. Finally, both groups need to give feedback for each other and the teacher as well.

According to this guideline, one consideration in the report phrase is there was only a limited amount of time to complete this task. Lee (2000) strongly recommends that teachers should set strict time limits. Such pressure will make students feel more obliged and thus motivated task quickly (Honeyfield, 1993; Oxford, 2006; Skehan, 1996). Then, another feature of this stage is the main task was carried out by the form of role-play. Ellis (2003, p6) indicated that role-play tasks attain interactional "authenticity" and reveal "situational authenticity". In other words, it helps students manage real-life situations commonly used language expressions, forcing students to think "on their feet". Moreover, the speaking class needs to create opportunity as much as possible for students to practice and exposure their speaking skill, while role-play is the best choice because students must precede interaction of the target language during their full performance (Ments, 1999). Furthermore, role-play is a efficient technique for students to promote learning by doing (Long, 1985) When students were assigned a situation to role play in, they had put effort to think of the appropriate language that could be used to express their views and thoughts for communication. It also helped them to acquire speaking skill and oral fluency. In addition, the implement of role-play echoing the studentscentered TBLT concept constructs the more natural utterance climate; therefore they are totally uncontrolled by the teachers and could make mistakes in a non-threatening environment. Finally, this role-play offers students and the teacher chances to evaluate their learning progress and their level of language.

Deserving to be mentioned that the implement of this report phrase imply certain SLA research theory. The first SLA perspective is the output hypothesis. According to Swain (1995) indication, the output hypothesis presents that learners have a unique opportunity to process language and the output process may be the trigger that force learner to focus on the means of expression needed in order to successfully convey their own intended meaning. In the report stage, the implement of role-playing job interview can be regard as students' output, while each pair of students in order to achieve a better performance consciously improve their language proficiency and make their output more precise, coherent, and appropriate. Learners' outputs do not just imply the process of acquiring knowledge, but also reveal learning at work (Swain, 1998\&2000). This comprehensible output provides the basic premise for another SLA theory that is cognitive hypothesis.

The cognitive theory of L2 learning regards second language acquisition as the process of conscious and reasoned thinking, involving the deliberate use of learning strategies (Skehan, 1998). In the view of the cognitive hypothesis, learners' performance engages in three basic aspects: fluency, accuracy, and complexity (ibid). Fluency refers to the learner's language performance in real-life context, accuracy to the learner's language competence to use the target language based on its fixed priciples, and complexity to the learner's ability to utilize more elaborate and complex structures and forms of the target language (Skehan, 1998\&2003). Ellis (2003) stated that TBLT approach can promote fluency, accuracy, and complexity in learners. In other words, the output offers learners with unique opportunities to motivate their cognitive resources (Izumi, 2002). In this current class, the role-play performance makes it possible for learners to notice a gap between what they expect to talk in the L2 and what they can say, which prompts them to consciously improve their current communication (fluency and accuracy) and progress and development (complexity) of the L2 in order to fill the gap.

\section{Language Focus}

The final stage, language focus places emphasis on language features used during the two previous stages (Willis, 1996). The language focus aims to give opportunities for students to analyze and practice specific linguistic features compromising the former task. In total, the TBL class proceeds from fluency to accuracy and fluency again, which strongly proved that although linguistic form is important, it is not the central part of the TBLT task model.

This current speaking class followed Willis suggestion mainly focus on form. In the process of implement, each student was given a table printed out the top six common questions that will be asked by interviewers in job interviews. And they need to write down at least one possible answer to each question. Then, the teacher checks students' answers and shares her answers by prepared printout, which instructs how to answer those questions in appropriate ways. Finally, the teacher recaps the whole lesson and makes a conclusion.

\section{THE ASSESSMENT OF TASK}

In this empirical TBL speaking lesson, the assessment stage applied for task cycle phrase. Willis (1996, p.58) considered that this stage is not only "the natural conclusion of the task cycle" which make it clear to summarize the outcome of the task, but also unfold a real picture for students to evaluate their own the task performance. In terms of the form of assessment in this class, it can be classified as the performance-based assessment (PBA), which stresses on any procedure of assessment that should concerns either the observation of real- world behavior or a real-life activity with raters to evaluate the performance (Bachman, 2002). Compared with traditional paper-and-pencil assessment, the PBA primary gives concern on getting an accurate picture on students' communicative competence, and also to infer students' ability beyond the learning situation to real-life communication (Norris, J., Brown, J. D., Hudson, T., \& Yoshioka, J., 1998). The feature of PBA roughly corresponds with the current class. It first requires students observe each other performance to justify whether they mentioned those key points that were taught in pre-task, and then they need to give each other some feedback. Finally the teachers also join in the process of assessment to comment students' task performance individually. 
The procedure of PBA was carried out though the form of peer-assessment and teacher-assessment. The peer assessment in higher education is a process whereby students draw on criteria to evaluate the work of their peers (Falchikov, 1995). The process can be formative or summative which can contain qualitative feedback blending the grading criteria used rather than a quantitative focus on the actual grade (Falchikov, 1993). For example, in this lesson, when one pair rates the performance from another pair, the student first justified whether their performance involve in those key points, and then detailed how they expand these key points. Also, this pair commented that the behaviors of another group are very confident. Moreover, in the PBA, students can possibly consider how they might improve on their performance of the task, and also students in peer-assessment will evaluate the task itself. Such information would be more trustworthy that will help the teacher to decide whether to use similar tasks in the future or look for a different type. In this class, the teacher also connects her own observation and peer assessment to give feedback of students' performance. She did not just comment like "well down" this kind of ambiguous utterance, instead the teacher specifically describes what student actual done in the task performance. Such descriptive assessment offers detailed information about the quality of students' task, which would help them more comprehensive realize their level of L2 language competence and performance. (Hibbard, 1996)

However, although the designers attempts to take more comprehensive consideration on planning this empirical lesson and prevent unnecessary mistakes as much as possible, there are still some limitation emerging in the implement of this class assessment. Firstly, the teacher found that the criteria of this task assessment are too vague. The only assessing criterion is to justify whether students integrate the useful information with their role-play. These limited criteria will restrict the development of peer-assessment; thereby causing some troubles during students give feedback, such as too short feedback or even ling-time silence among students. Also, this kind of criteria only explicit the importance of fluency of task report while it neglect aspects of accuracy and complexity. In the next lesson, the designer could a detailed criteria check list including how students dealt with communication problems, and even what language they learned from the task. Secondly, negative feedback is overlooked in the teacher assessment. Izumi (1998) suggested that negative feedback can offer students chances to notice discrepancies between their inter-language output and the target language. That means, negative feedback emphasized the accuracy of students' task performance. Therefore, neglect of negative feedback not only may mislead students to directly ignore language accuracy, but also will blocks the teacher to gather trustworthy information to efficient promote the next language focus stage.

\section{CONCLUSION}

This paper exemplifies a TBL speaking class regarding response of job interview to demonstrate the effectiveness and feasibility of TBLT approach. It illustrates that TBLT approach adopts student-centered paradigm and focuses on how to learn rather than what to learn. The task is central concept of TBLT approach when students carrying out the tasks, they do not concentrate on language features, but focus on meaning that the target language actual is used in everyday life. Then, this article elaborated how the empirical class efficient implies based on the Willis' TBL framework, among which the interpreting of task cycle took up considerable proportion that include analysis of the rational of role-play task and the explanation of certain SLA theorythe output hypothesis and the cognitive hypothesis. Finally, the paper acquired the format of PBA to generally evaluate student's task performance, and then discussed limitation of the implement of task assessment. In short, TBLT approach is an innovation of language teaching and learning, it is worth for us to further explore its application and promote it into a more deep-going way.

\section{REFERENCES}

[1] Branden, K. (2006). Task-based language education. Cambridge: Cambridge University Press.

[2] Bachman, L. (2002) "Some reflections on task-based language performance assessment", Language Testing, 19, pp.453-476

[3] Ellis, R. (2003) Task-based language teaching. Oxford, UK: Oxford University Press

[4] Falchikov N. (1995) "Peer feedback marking: developing peer assessment" Innovat Educ Teach Int, 32(2), pp.175-187

[5] Falchikov N. (1993) "Group process analysis: self and peer assessment of working together in a group”, Educ Tech Train Int., 30, pp.275-284.

[6] Honeyfield, J. (1993) Responding to task difficulty. Singapore: Regional Language Center.

[7] Izumi, S. (2002) "Output, input enhancement, and the noticing hypothesis: an experimental study on ESL relativization”, Studies in Second Language Acquisition 24 pp. 541-77.

[8] Izumi, S. (1998) "Negative feedback in adult NS-NNS task-based conversation", Paper presented at the annual meeting of the American Association for Applied Linguistics, Seattle, WA.

[9] Jaques, D. (2000) Learning in Groups: A Handbook for Improving Group Work. London: Kogan Page.

[10] Lee. J. (2000) Tasks and Communicating in Language Classrooms. USA: McGraw-Hill

[11] Long, M. (1985) A Role for Instruction in Second Language Acquisition. Clevedon Avon: Multilingual Matters.

[12] Nunan, D. (1989) Designing Tasks for The Communicative Classroom. Cambridge: Cambridge University Press.

[13] Oxford, R. (2006) "Task-based language teaching and learning: An overview", The Asian EFL Journal Quarterly, 8(3), PP.94-121.

[14] Prabhu, N. S. (1987) Interactive Language Teaching, Cambridge: Cambridge University Press.

[15] Richards, J. \& T. Rodgers. (1986) Approaches and Methods in Language Teaching. Cambridge: Cambridge University Press.

[16] Skehan, P. (1996) "A Framework for the Implementation of Taskbased Instruction”, Applied Linguistics, 17(1), pp.38-62.

[17] Swain, M. (1995) Principles and practice in the study of language. Oxford: Oxford University Press.

[18] Swain, M. (1998) Focus on Form in Classroom Second Language Acquisition. Cambridge: Cambridge University Press.

[19] Swain, M. (2000) Sociocultural Theory and Second Language Learning. Oxford: Oxford University Press.

[20] Skehan, P. (1998) A Cognitive Approach to Language Learning. Oxford: Oxford University Press. 
[21] Skehan, P. (2003) "Tasks in L2 learning and teaching. Language", Teaching 36 pp.1-14.

[22] Skehan, P. (1998) A Cognitive Approach to Language Learning. Oxford: Oxford University Press.

[23] Van Ments, M. (1999) The effective use of role-play. London: Kogan Page.

[24] Willis, J. (1996) A Frame Work for Task Based Learning. U.K.: Longman Addison-Wesley.

[25] Willis, J. (2007) Doing task based teaching. Oxford: Oxford University Press. 